\title{
Effect of visual and tactual stimulation on learning abstract forms: A replication
}

\author{
JAMES K. WALSH* \\ St. Louis University, St. Louis, Mo. 63103
}

Visual (V), tactual (T), and combined visual and tactual (VT) training and testing of abstract shapes were explored in three experiments using Ss from undergraduate psychology courses. In a recognition test, $V$ and VT training were shown to be superior to $T$ training. Visual and VT testing had a significant effect over $T$ testing. A recall experiment showed that $V$ training and VT training were both superior to $T$ training. The third experiment showed that Ss presented the $\mathrm{V}$ stimuli before the $\mathrm{T}$ stimuli recalled significantly more than those Ss presented the reverse order. The results of the experiments were interpreted as indicating the superiority of visual information processing over tactual information processing. Concurrent $\mathrm{V}$ and $\mathrm{T}$ stimulation resulted in performance similar to that of exclusive $\mathrm{V}$ stimulation.

Fico \& Brodsky (1972) supported previous findings of Lobb (1965) and Cashdan (1968) that visual learning was superior to tactual learning of abstract shapes in both recognition and recall testing. Contrary to Cashdan \& Zung (1970), combining visual and tactual stimulation resulted in decreased performance as compared with exclusive visual stimulation.

Investigations of crossmodal transfer have resulted in inconsistent results. Fico and Brodsky supported Lobb's earlier findings that the visual followed by tactual order of stimulation was significantly superior to the reverse order. However, Gaydos (1956) and Cashdan (1968) have suggested that the tactual-visual order of stimulation yields superior performance on transfer tasks.

The present research was an attempt to clarify the relationship of combined visual and tactual stimulation and also crossmodal transfer. Essentially, this is a replication of the Fico and Brodsky study. An experiment investigating pretraining was ommitted for two reasons: (a) no systematic pretraining effects were found in the original study, and (b) previous tactual experience was investigated through a postexperimental questionnaire in the performed experiments.

\section{EXPERIMENT I}

Method

\section{Subjects}

In all three experiments, undergraduate psychology students were used as Ss and received course credit for participation. Each group consisted of three male and three female Ss, and each $S$ was tested individually.

*Donald I. Tepas sponsors this paper and takes full editorial responsibility for its contents. Requests for reprints should be sent to $J$. Walsh, Department of Psychology, St. Louis University, St. Louis Mo. 63103. The author wishes to thank James Fico and Howard Brodsky for supplying the abstract shapes and other information concerning the original study.

\section{Apparatus}

The shapes used for tactual stimulation were cut from $3 / 8$-in. white styrofoam and measured $4 \frac{1}{2}$ in. at their largest dimension. Each of the 40 shapes had a minimum of 5 and a maximum of 13 points and was mounted on a black $8 \times 9$ in. Masonite board to insure a uniform background. Tactual stimuli were presented in a black box in which the $S$ could feel, but not see, the shapes. All shapes were presented in a uniform manner. Color slides of the shapes were used as the visual stimuli. The shapes were projected on a screen $4 \mathrm{ft}$ in front of the $S$ at actual size and at each S's eye level. Separate sets of both tactual and visual stimuli were used during training and testing. The shapes were those used by Fico and Brodsky.

\section{Procedure}

Fifty-four Ss were assigned randomly to groups of three males and three females. The nine groups were differentiated on the basis of modality of training (V, VT, T). Each S was instructed and tested in exactly the same manner as in the original study. Following the recognition test, each $S$ filled out a questionnaire pertaining to previous experience.

\section{Results}

Table 1 shows the totals for correct positive ("yes") responses expressed as proportions of the total possible number of correct responses. Chance performance for each $\mathrm{S}$ was 10 correct recognitions, and each cell of six Ss had a possible 60 positive recognitions.

Significant effects for the training modality $[\mathrm{F}(2,45)$ $=25.84, \mathrm{p}<.01]$ and the testing modality $[\mathrm{F}(2,45)=$ $12.84, \mathrm{p}<.01]$ were revealed by an analysis of variance (Training by Testing). A Newman-Keuls analysis showed both visual training and visual-tactual training to be superior to tactual training, and also visual testing and visual-tactual testing were shown to be superior to tactual testing, $p<.05$ in each case. Visual and visual-tactual training or testing were not shown to be different. No difference was found between males and females or between tactually naive and tactually experienced Ss, as judged from the posttest questionnaire. Only those Ss who indicated at least 6 months of concentrated manual experience (i.e., playing musical instruments, assembly line work with hands, typist, etc.) were considered tactually experienced.

\section{EXPERIMENT II \\ Method}

Three recall groups were formed on the basis of modality of learning (V, VT, T) by randomly assigning three male and three female Ss to each group. The instructions, training procedure, and stimuli were identical to those used in Experiment I. Recall testing, as introduced by Rock \& Victor (1964), immediately followed the training period. Each $S$ was asked to draw as many of the shapes as he could during a 10-min period. The shapes were scored by a grader who was blind to the experimental design. Reliability was ensured through the use of a strict scoring criterion. The $\mathrm{E}$ also scored the drawings, and $99 \%$ of these 
Table 1

Proportion of Total Correct Positive Recognition Scores With Six Ss Per Cell

\begin{tabular}{ccccc}
\hline & \multicolumn{3}{c}{ Testing } & \\
\cline { 2 - 4 } Training & $\mathrm{V}$ & $\mathrm{VT}$ & $\mathrm{T}$ & Total \\
\hline V & .742 & .692 & .517 & .650 \\
VT & .742 & .729 & .567 & .679 \\
T & .517 & .463 & .521 & .500 \\
Total & .667 & .628 & .531 & .610 \\
\hline
\end{tabular}

Note-Chance performance was a proportion of .500 positive recognition for each cell.

scores were identical to those of the blind grader. After the recall period, each $S$ filled out the same questionnaire as used in Experiment I.

\section{Results and Discussion}

Visually trained Ss drew 16 shapes judged as correct, VT Ss drew 17 correct shapes, and T Ss drew just 1 shape correctly. A control group of six Ss drew no shapes that were judged correct. A Newman-Keuls analysis revealed that both V-trained and VT-trained Ss performed significantly better than the T-trained group $(p<.05)$. No difference was found between the V-trained and VT-trained groups or between the T-trained group and the control group. Once again, sex or previous tactual experience data did not yield any differences.

Experiment II supported Experiment I in indicating the superiority of both V and VT training over $T$ training. The similarities in performance of the $V$ and VT groups in both Experiment I and Experiment II suggests that, in some way, tactual information is not being totally processed, or that simultaneous processing of visual and tactual information results in some confusion.

\section{EXPERIMENT III Method}

Two groups were selected randomly, each having three male and three female Ss. One group (V-T) trained visually for $15 \mathrm{sec}$, followed by $15 \mathrm{sec}$ of tactual training on each of the 20 shapes. There was no interstimulus interval to equate total training time for each $S$ with that of the first two experiments, namely $10 \mathrm{~min}$. The second group (T-V) followed the same procedure except for the reversal of the order of the training modalities. The stimuli were presented in the same order as in Experiments I and II. Recall testing was identical to that in Experiment II.

\section{Results and Discussion}

Ss of Group V-T correctly recalled a total of 18 stimuli, while Ss of Group T-V recalled 7 stimuli correctly. The difference was found to be significant $[t(10)=3.47, p<.01]$. Group V-T learned the shapes identically to Group V in Experiment II, except that, after $15 \mathrm{sec}$ of visual stimulation, they received tactual stimulation in place of the interstimulus interval. Group T-V differed from Group V-T only in the order of training modalities. The results may indicate the difficulty of integration of visual experience with previous tactual experience.

\section{CONCLUSIONS}

The present research supports the findings reported by Fico \& Brodsky (1972) and Lobb (1965) pertaining to the temporal order of presentation of stimulus modalities, and further clarifies the inconsistent results of Cashdan (1968). The visual-tractual order of presentation was found to be superior to the tactual-visual order. However, the present author cannot agree with the original authors' proposal that tactual stimulation following visual stimulation must be treated as distraction rather than as a learning experience. Since Group V-T Ss knew what the shape looked like before tactual stimulation, they may have been able to integrate tactual information more readily than Group T-V. Group T-V may have found tactual information less useful without previous visual information because exclusive tactual information may be harder to process. As Cashdan suggested, tactual stimuli seem to be perceived piece by piece rather than in entirety as are visual stimuli. Previous visual information would allow for integration of each piece of tactual information into the visual perception of the entire shape. On the contrary, tactual stimulation presented before the visual stimulation may act as a distraction to the integration of sensory information. In other words, the tactual perception of the shape has been pieced together and any contradiction between the image formed through tactual information processing and the perceived visual information may be a disturbance to the integration of information from the two sense modalities.

The task of the $S$ to integrate tactual information, perceived in a piece-by-piece fashion with an already perceived shape, would seem to be easier than the task of forming an "image" through tactual perception and then comparing that "image" to the visual perception. The latter case would seem to be more confusing, and the effort of forming an "image" piece by piece from tactual sitmulation would seem to hinder the processing of the visual stimulus information. This statement is supported by the results shown in Table 2 . Group V-T performed similarly to Group V. If the tactual stimulation acted as a distractor, one would expect a lower performance by Group V-T than by Group V.

The results from the present experiments do not agree with the conclusion reached by Fico and Brodsky, that combined tactual and visual stimulation results in decreased performance. As shown. in Tables 1 and 2, combined training modalities resulted in very similar performance, as did exclusively visual stimulation. These data are in agreement with previous findings of Cashdan \& Zung (1970), which show that simultaneous visual and tactual stimulation yield similar results to those of exclusive visual stimulation. The similarity in performance of VT-trained Ss and V-trained Ss may suggest that: (a) the simultaneous integration of information from both senses is difficult to process to its full capacity, (b) visual information processing is dominant and in some way hinders the processing of tactual information, or (c) tactual information is virtually ignored by humans when visual information is available.

Table 2

Summary of Recall Groups Training in Seconds

\begin{tabular}{lccc}
\hline Group & $0-15$ & $15-30$ & Total \\
\hline T & T & - & .008 \\
T-V & T & V & .058 \\
V & V & - & .133 \\
VT & V and T & - & .142 \\
V-T & V & T & .150 \\
\hline
\end{tabular}

Note-Chance performance for recall groups was .000 proportion of correct responses. 


\section{REFERENCES}

Cashdan, S. Visual and haptic form discrimination under conditions of successive stimulation. Journal of Experimental Psychology, 1968, 76, 215-218.

Cashdan, S., \& Zung, B. J. Effect of sensory modality and delay on form recognition. Journal of Experimental Psychology, $1970,86,458-460$.

Fico, J. M., \& Brodsky, H. S. The effect of visual and tactual stimulation on learning of abstract forms. Psychonomic Science, 1972, 27, 246-248.
Gaydos, H. F. Intersensory transfer in the discrimination of form. American Journal of Psychology, 1965, 19, 175-187.

Lobb, H. Vision versus touch in form discrimination. Canadian Journal of Psychology, 1965, 19, 175-187.

Rock, I., \& Victor, J. Vision and touch: An experimentally created conflict between the two senses. Science, 1964, 143, 594-596.

(Received for publication August 15, 1973.)

\section{Apparent double alternation in the rat: A failure to replicate}

\author{
SARAH PITT, STEPHEN F. DAVIS* \\ and BOBBY R. BROWN \\ Austin Peay State University, Clarksville, Tenn. 37040
}

Two groups of rats, run under odor-maximizing and odor-minimizing trial sequences, served as Ss in a three-phase study investigating the role of olfactory cues in the acquisition, extinction, and reacquisition of double-alternation patterning in the runway. The 104 acquisition trials and 8 extinction trials were run in an apparatus having hardware-cloth tops. The tops of the apparatus were covered by a transparent plastic sheet during the 32 reacquisition trials. During acquisition, double-alternation patterning failed to develop. However, significant extinction differences developed in the goal measure. During reacquisition, significant double-alternation patterning was shown by the odor-maximizing Ss. The results strongly suggest that the effective olfactory cues are airborne, and dissipate appreciably, but not completely, in the runway utilizing wire-mesh tops.

The amount of research investigating the role and nature of olfactory cues in animal maze learning has literally mushroomed in recent years. The initial report directly concerned with the possibility that rat Ss exuded discriminably different odors on reward (R) and nonreward $(\mathrm{N})$ trials would appear to be that of Ludvigson \& Sytsma (1967). This investigation showed that rat Ss were capable of learning a double-alternation pattern only under odor-maximizing conditions. A subsequent study by Seago, Ludvigson, \& Remley (1970) replicated this finding, and further indicated that anosmic Ss were incapable of learning the pattern. A study by Davis (1970), using mice as Ss, also corroberated the Ludvigson \& Sytsma (1967) data. Since the publication of the Ludvigson \& Sytsma (1967) study, research has indicated the strong possibility that odor may be an influential factor in a number of animal learning phenomena, such as latent extinction (Pratt \& Ludvigson, 1970), the depression effect (Davis \& Ludvigson, 1969), the partial reinforcement extinction effect (Prytula, Bridges, Anderson, \& Hayes, 1972; Davis, 1973; Prytula, Cox, \& Bridges, 1973), and T-maze

*Requests for reprints should be sent to Stephen F. Davis, Department of Psychology, Austin Peay State University, Clarksville, Tenn. 37040. This paper is sponsored by Robert $\mathbf{E}$ Prytula, who takes full editorial responsibility for its contents. performance (Morrison \& Ludvigson, 1970; Means, Hardy, Gabriel, \& Uphold, 1971).

If odor cues are indeed influential, and the growing body of literature would certainly indicate that they are, then some attention must be given to methods for controlling these odors. As noted in a recent article (Davis, 1973), such techniques as swabbing the apparatus with water or various chemical disinfectants, exhausting the runway air, and using anosmic Ss have been suggested and employed. It is interesting to note that the majority of the odor studies have been conducted in runways having Plexiglas lids, which serve to retain the odors in the apparatus. Recent studies reported by Phillips \& Bloom (1971) and Bloom \& Phillips (1973) have indicated that exhausting the runway air appears to be an effective odor control procedure. This would suggest the possibility that the effective odorants are airborne. At this point one might be wondering how rapidly the odor cues would dissipate in an apparatus lacking the retentive feature of the Plexiglas lid. Simply using an apparatus having wire-mesh tops, which would be more conducive to the dissipation of odors, might provide an effective and less troublesome odor control procedure. The present study, which was essentially a replication of the Ludvigson \& Sytsma (1967) study, was designed to investigate this possibility.

\section{METHOD \\ Subjects}

Fourteen naive male albino rats, purchased from the Holtzman Co., Madison, Wis., served as Ss. The Ss were approximately 120 days old at the beginning of the experiment and were housed in individual cages with water always available.

\section{Apparatus}

The apparatus consisted of a single straight runway $(11.43 \mathrm{~cm}$ wide, $12.70 \mathrm{~cm}$ high). A $28.10-\mathrm{cm}$ gray startbox was separated from a 91.44-cm black run section by a Masonite guillotine door. A second guillotine door separated the run section from a $30.48-\mathrm{cm}$ black goalbox. Raising the start door activated a Standard Electric Timer (start time). Passing through a photoelectric beam located $15.24 \mathrm{~cm}$ beyond the start door stopped the first timer and activated a second timer (run time). Breaking a second beam, located $76.20 \mathrm{~cm}$ beyond the first beam, stopped the second timer and started a third timer (goal time). Breaking a third beam, located $5.08 \mathrm{~cm}$ in front of the goal cup, stopped the third timer. The plastic goal cup, recessed into the back wall of the goalbox, was $4 \mathrm{~cm}$ high, $4 \mathrm{~cm}$ wide, and 